\title{
Matrix metalloproteinase-3 promoter polymorphisms but not dupA-H. pylori correlate to duodenal ulcers in $\mathrm{H}$. pylori-infected females
}

\author{
Yi-Chun Yeh ${ }^{1}$, Hsiu-Chi Cheng ${ }^{2,3}$, Wei-Lun Chang ${ }^{2,3}$, Hsiao-Bai Yang ${ }^{4,5}$, Bor-Shyang Sheu $2,3^{*}$
}

\begin{abstract}
Background: This study investigated if the H. pylori dupA genotype and certain host single nucleotide polymorphisms (SNPs) of matrix metalloproteinases (MMPs) and their inhibitors (TIMPs), including MMP-3, MMP-7, MMP-9, TIMP-1 and TIMP-2, might correlate with ulcer risk of H. pylori-infected Taiwanese patients.

Results: Of the 549 H. pylori-infected patients enrolled, 470 patients (265 with gastritis, 118 with duodenal ulcer, and 87 with gastric ulcer) received SNPs analysis of MMP-3-1612 6A $>5$ A, MMP-7 -181 A > G, MMP-9 exon 6 A > G, TIMP$1_{372} \mathrm{~T}>\mathrm{c}$ and TIMP-2-418 G > c by PCR-RFLP. The 181 collected $\mathrm{H}$. pylori isolates were detected for the dupA genotype by PCR. The rates of dupA-positive $H$. pylori infection were similar among patients with duodenal ulcer (22.8\%), gastric ulcer (20.0\%), and gastritis (25.5\%) $(p>0.05)$. Males had higher rates of duodenal ulcer and gastric ulcer than females $(p<0.01)$. Of $\mathrm{H}$. pylori-infected patients, the MMP-3 6A6A genotype were more common in patients with duodenal ulcers than in those with gastritis $(87.7 \%$ vs. $74.9 \%, p<0.05)$ in females. This genotype had a 2.4-fold (95\% Cl: 1.02-5.66) increased risk of duodenal ulcer, compared to those with the $5 \mathrm{~A}$ carrier. Combining the MMP-3/TIMP-1 genotype as 6A6A/CC, the risk of duodenal ulcer increased up to 3.6 fold $(p<0.05)$ in H. pylori-infected females.
\end{abstract}

Conclusions: The MMP-3 promoter polymorphism, but not the dupA-status, may correlate with susceptibility to duodenal ulcer after H. pylori infection in Taiwanese females.

\section{Background}

Helicobacter pylori infection leads to chronic gastritis and in some individuals, to peptic ulcer disease or even gastric carcinoma [1]. Diverse outcomes may depend on complex interactions among bacterial virulence factors, host genetics, and environmental factors [2,3]. In Taiwan, despite the nearly $100 \%$ prevalence of the so-called triple-genopositive $c a g A-v a c A-b a b A 2$ virulent $H$. pylori infections, there is a lack of correlation to different disease outcomes $[4,5]$. It will be useful for Taiwan to validate new virulence factors or any host genomic predisposition in relation to severe H. pylori-infected clinical outcomes.

Recently, a duodenal ulcer-promoting gene A (dupA) encompassing $j h p 0917$ and $j h p 0918$ has been suggested to lead into higher IL-8 production of epithelial cells

\footnotetext{
* Correspondence: sheubs@mail.ncku.edu.tw

${ }^{2}$ Institute of Clinical Medicine, National Cheng Kung University Hospital, Medical College, Tainan

Full list of author information is available at the end of the article
}

and thus, triggering dense neutrophil infiltration and increased risk of duodenal ulcers 2[6]. However, even in such large-scale validation, those with duodenal ulcer have a nearly $55 \%$ dupA-positive infection [6]. Moreover, prevalence of $d u p A$ and relationships between dupA-positive H. pylori and clinical outcomes are different in distinct populations [7-11]. It may indicate that $d u p A$ serves a promoting role leading to duodenal ulcer after $H$. pylori infection. Alternatively, it is necessary to validate host factors that predispose patients to gastroduodenal ulcer, especially with $\operatorname{dupA}$-negative infection.

$H$. pylori infection stimulates the production of proinflammatory cytokines, such as IL-1, which play important roles in gastric inflammation and physiology. However, IL-1 beta or IL-1RN polymorphisms are not associated with gastric ulcer in the Taiwanese population [12].

Matrix metalloproteinases (MMPs) are a family of enzymes that degrade most extracellular matrix and
C Biomed Central

(c) 2010 Yeh et al; licensee BioMed Central Ltd. This is an Open Access article distributed under the terms of the Creative Commons Attribution License (http://creativecommons.org/licenses/by/2.0), which permits unrestricted use, distribution, and reproduction in any medium, provided the original work is properly cited. 
correlate with ulcer formation or repairs [13]. H. pylori infection can up-regulate MMP-3, MMP-7, and MMP-9 in the gastric mucosa and even sera [14-16]. A largescale German survey has further validated that the single-nucleotide polymorphisms (SNP) genotype as MMP-7-181 G allele and MMP-9 exon $6_{6}$ A allele increase the risk of gastric ulcer after $H$. pylori infection [17]. A deletion at MMP-3 promoter -1612, and A to G substitution at MMP-7 promoter -181 may affect transcriptional activity, leading to alterations in gene expression $[18,19]$. Moreover, A to G substitution at MMP-9 exon 6 causes the amino acid change required for binding to its substrate and affects its binding ability [20].

Although MMP activity is in general counteracted by endogenous tissue inhibitors (TIMPs) [21], there remains no data to check whether TIMP-1 and TIMP-2 SNP genotypes relate to the risk of gastroduodenal ulcer after $H$. pylori-infection. As such, this study surveyed if the H. pylori dupA genotype and certain SNP genotypes of MMP-3, MMP-7, MMP-9, TIMP-1, and TIMP-2 predispose $H$. pylori-infected Taiwanese patients to ulcer risks.

\section{Methods}

\section{Patients and study design}

Five hundred and forty-nine consecutive H. pyloriinfected patients documented by upper gastrointestinal endoscopy at National Cheng Kung University Medical Center, Tainan, Taiwan were enrolled. All were genetically unrelated ethnic Han Chinese from Tainan City and the surrounding regions. None had been treated with NSAIDs, proton pump inhibitor, or any antibiotics within two weeks prior to panendoscopy on enrollment, or a past history of anti-H. pylori treatment and peptic ulcer. The hospital Ethics Committee approved the study.

After obtaining informed consent, 470 patients had provided enough blood samplings for SNPs analysis of MMP3-1612 6A > 5A, MMP-7 $-181 \mathrm{~A}>\mathrm{G}$, MMP-9 exon $6 \mathrm{~A}>\mathrm{G}$, TIMP-1 $372 \mathrm{~T}>\mathrm{C}$ and TIMP-2 $-418 \mathrm{G}>\mathrm{C}$ by PCR-RFLP. Aside from endoscopic diagnosis for clinical diseases, at least three topographic gastric biopsies were sampled for histology or H. pylori culture, one each from the antrum, corpus, and cardia. These were stained with haematoxylin and eosin and reviewed for the H. pylori-related histology by the updated Sydney's system $[4,22,23]$.

In addition, the study collected $181 \mathrm{H}$. pylori isolates for the detection of dupA genotype by PCR. One hundred and three isolates were collected from randomly selected patients who had agreed to undergo SNP analysis, while 78 isolates were from patients without SNP analysis. The $H$. pylori culture were conducted from the two additional gastric biopsies collected during the same endoscopy and processed with the method applied in previous publications $[4,22]$.
For those with positive $H$. pylori culture, the isolates were extracted for genomic DNA to be analyzed for the dupA genotypes by PCR. The extraction of DNA was done with the same method as described previously $[4,22]$. Positive $H$. pylori infection was defined by positive histology or culture.

\section{Genotypes of SNPs in MMPs and TIMPs}

Peripheral blood $8 \mathrm{ml}$ was obtained from each subject for genomic DNA, which was extracted from peripheral blood mononuclear cells according to the manufacturer's instructions (Viogene, Taipei, Taiwan). Five SNPs

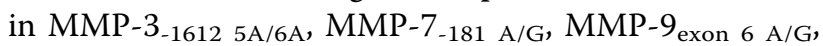
TIMP-1 $372 \mathrm{C} / \mathrm{T}$, and TIMP-2 $-418 \mathrm{G} / \mathrm{C}$ polymorphisms were determined by PCR-RFLP assays [18,24-26].

Using the extracted DNA as template, the regions of each MMP and TIMP were amplified by PCR using commercially available kits (GoTaq ${ }^{\circ}$ Green Master Mix, Promega, Madison, WI, USA) following the manufacturer's instructions. The sequences of primers, PCR conditions, and restriction enzymes (obtained from New England Biosciences, U.S.) used were summarized in Table 1. After digestion, the products were separated by electrophoresis on a $4 \%$ agarose gel. The MMP and TIMP genotypes were shown as different gel examples (Figure 1).

Quality control for genotyping was achieved by including in each amplification a negative PCR control sample and three positive control samples for each SNP analyzed (homozygous for allele 1, heterozygous, and homozygous for allele 2). At least $10 \%$ of the samples were run twice in separate assays to reveal $100 \%$ concordance of the genotype designation for all of the polymorphisms. For the positive controls, the genopositive products were confirmed by direct sequencing.

\section{Detection of dupA gene by PCR}

The dupA-positive $H$. pylori was determined by positive PCR amplifications of at least 2 regions (jhp0917 and jhp0918) of the gene using two specific primer pairs (Figure 2) for strains $J 99$ and 26695 as templates (Table 1) [6]. DNA $2 \mu \mathrm{l}$ were added to $50-\mu \mathrm{l}$ reaction mixture, containing $1 \times$ PCR buffer, $1.5 \mathrm{mM} \mathrm{MgCl} 2,0.2 \mathrm{mM}$ dNTP (Protech, Taiwan), $0.2 \mu \mathrm{M}$ primers and $1 \mathrm{U}$ Taq DNA polymerase (Fermentas, USA). PCR was performed with a thermal cycler (2720 thermal cycler; Applied Biosystems). The mixture was stored at $4{ }^{\circ} \mathrm{C}$ and the PCR products were separated by electrophoresis on $2 \%$ agarose gel. The gels were stained with ethidium bromide and visualized under UV illumination.

\section{Statistical analysis}

Statistical analysis was performed with the SPSS software (SPSS 12, Chicago, IL, USA). The $\chi^{2}$ test, Fisher's exact test or Mann-Whitney $U$ test were used as appropriate to 
Table 1 The PCR primers used in the study

\begin{tabular}{|c|c|c|c|c|}
\hline SNP/gene & Primer sequence $\left(5^{\prime} \bullet 3^{\prime}\right)$ & Size (bp) & Restriction enzyme & Reference \\
\hline \multirow[t]{3}{*}{ MMP-3-1612 5A/6A } & GATTACAGACATGGGTCACG & 120 & $x m n !$ & Shibata et al, 2005 \\
\hline & TाTCAATCAGGACAAGACGAAGTTा & & $6 \mathrm{~A}: 120 \mathrm{bp}$ & \\
\hline & & & $5 A: 97 b p+23 b p$ & \\
\hline \multirow[t]{3}{*}{$M M P-7_{-181} \mathrm{~A} / \mathrm{G}$} & TGGTACCATAATGTCCTGAAT & 150 & EcoRI & Jormsjö et al, 2001 \\
\hline & TCGTTATTGGCAGGAAGCACACAATGAATT & & A: $150 \mathrm{bp}$ & \\
\hline & & & $\mathrm{G}: 120 \mathrm{bp}+30 \mathrm{bp}$ & \\
\hline \multirow[t]{3}{*}{$M M P-9_{\text {exon6 } \mathrm{A} / \mathrm{G}}$} & CCATCCATGGGTCAAAGAAC & 295 & Smal & Shibata et al, $2005 *$ \\
\hline & GGGCTGAACCTGGTAGACAG & & A: 295 bp & \\
\hline & & & G: $192 b p+103 b p$ & \\
\hline \multirow[t]{3}{*}{ TIMP-1 $372 \mathrm{C} / \mathrm{T}$} & GCACATCACTACCTGCAGTC & 175 & BssSI & Wollmer et al, 2002 \\
\hline & GAAACAAGCCCACGATTTAG & & $\mathrm{T}: 175 \mathrm{bp}$ & \\
\hline & & & $C: 152 b p+23 b p$ & \\
\hline \multirow[t]{3}{*}{ TIMP-2 - $418 \mathrm{G} / \mathrm{C}$} & CGTCTCTTGTTGGCTGGTCA & 304 & BsoBl & Zhou et al, 2004 \\
\hline & CCTTCAGCTCGACTCTGGAG & & $c: 253 b p+51 b p$ & \\
\hline & & & G: $230 b p+51 b p+23 b p$ & \\
\hline jhp0917_1 & TGGTITCTACTGACAGAGCGC & 307 & - & Lu et al., 2005 \\
\hline jhp0917_2 & AACACGCTGACAGGACAATCTCCC & & & \\
\hline jhp0917_3 & GCCTAAGACCTCAAACTAGC & 296 & - & This study * \\
\hline jhp0917_4 & CATTCTGTCAAGAGCTACC & & & \\
\hline jhp0918_1 & CCTATATCGCTAACGCGCGCTC & 276 & - & Lu et al., \\
\hline jhp0918_2 & AAGCTGAAGCGTTTGTAACG & & & 2005 \\
\hline jhp0918_3 & GCTAGAAAGATCAACGGAAC & 216 & - & This study* \\
\hline jhp0918_4 & CACTTGTCTGGCTCTCAT & & & \\
\hline
\end{tabular}

*The primers were self-designed by applying Primer 3 and the restriction enzyme was selected based on the reference of Shibata et al, 2005.

validate the $\operatorname{dupA}$ prevalence rates, histological severity, or SNP genotypes of MMPs and TIMPs between patients with and those without ulcers. A $p<0.05$ was taken as significant. All test significances were validated by twotailed analysis. The odds ratios (OR) and 95\% confidence intervals $(\mathrm{CI})$ were used to estimate the risk to get gastroduodenal ulcer in these $H$. pylori-infected subjects.

\section{Results}

\section{Demographic features of the study subjects}

Of the $470 \mathrm{H}$. pylori-positive dyspeptic patients who provided blood samples for SNP analysis, 276 were females and 194 males, with median age of 47.2 years (range, 1687 years). Endoscopic diagnoses included 265 with gastritis, 118 with duodenal ulcers, and 87 with gastric ulcers. Their demographics and histology after H. pylori infection were listed in Table 2. Patients with gastritis and duodenal ulcer had higher gastric inflammation in the antrum than those with gastric ulcers $(p<0.05)$. Among $H$. pylori-infected patients, males had higher rates of duodenal and gastric ulcers than females (51.7\% vs. $30.9 \%$ and $58.6 \%$ vs. $30.9 \%, p<0.001$, respectively).

\section{Prevalence of dupA H. pylori infection in patients}

One hundred and eighty-one $H$. pylori strains were successfully obtained (Figure 3 ). The concordance of two
PCR primer pairs was $95.3 \%$ (41/43). Only two isolates were $\operatorname{dup} A$-positive by single primer pairs. Forty-three isolates $(23.8 \%)$ were genopositive for $\operatorname{dup} A$, of which six $(20.0 \%)$ were from patients with gastric ulcer, $13(22.8 \%)$ from patients with duodenal ulcer, and 24 (25.5\%) from gastritis patients. The prevalence rates of $d u p A$-positive $H$. pylori infection were similar between patients with and those without ulcers $(p>0.05)$.

\section{MMP and TIMP genotypes and the $\mathrm{H}$. pylori-related} gastro-duodenal ulcer

The $470 \mathrm{H}$. pylori-infected patients with SNP analysis had $>99 \%$ average genotyping success and the distributions of all SNPs were in Hardy-Weinberg equilibrium $(p>0.05)$. Since the ulcer rate had gender differences (Table 2), five genotype distributions were analyzed and separated by gender. There were no significant differences in genotype distributions of MMP-7 $-181 \mathrm{~A} / \mathrm{G}$, MMP-9 exon $6 \mathrm{~A} / \mathrm{G}$, TIMP-1 372 T/C and TIMP-2-418 G/C between patients with different clinical diagnoses $(p>0.05)$ (Table 3).

There was a higher rate of MMP-3 6A6A genotype in patients with duodenal ulcers than in patients with gastritis $(87.7 \%$ vs. $74.9 \%, p<0.05)$. H. pylori-infected subjects with the MMP-3 6A6A genotype had a 2.4-fold 


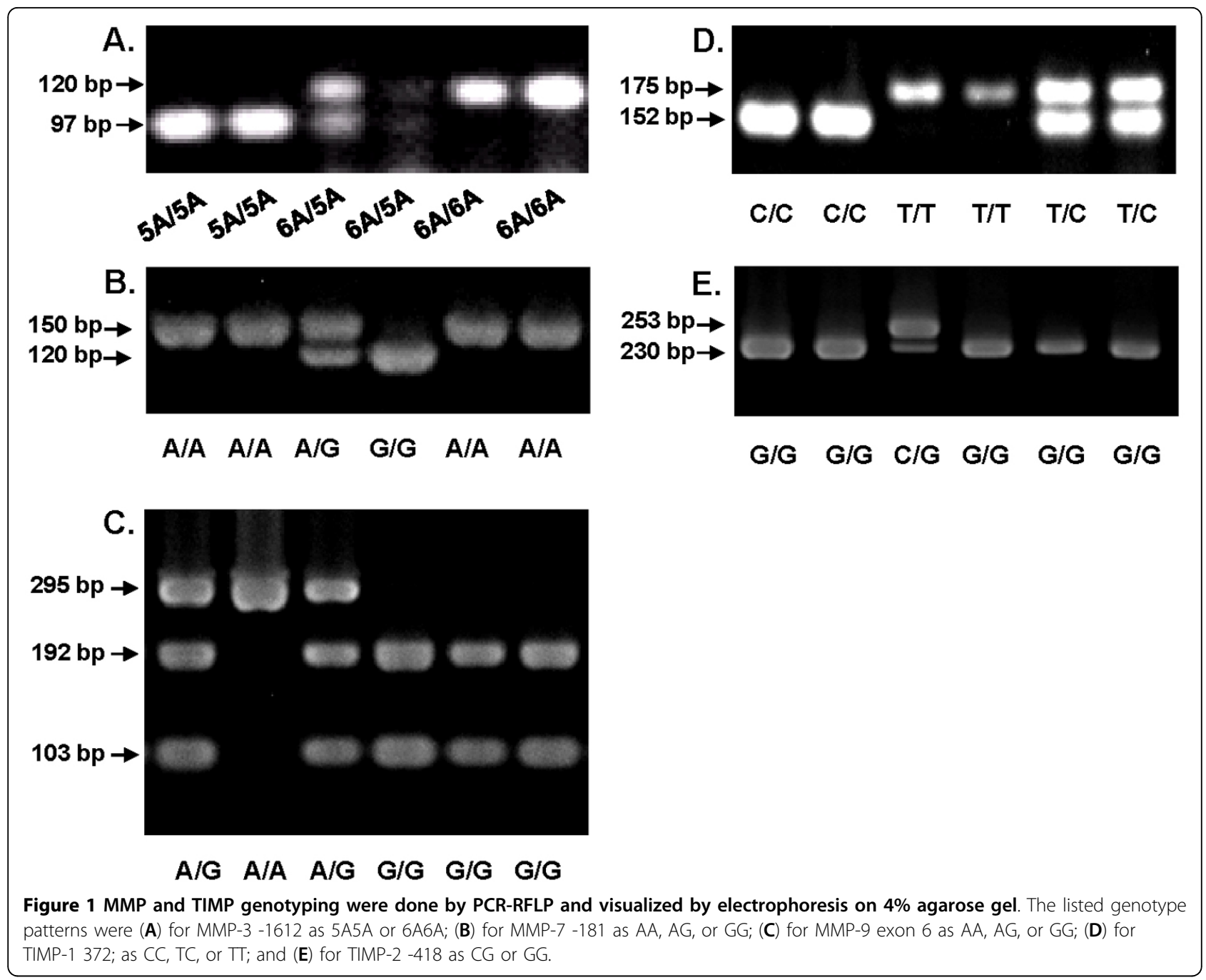

(95\% CI: 1.02-5.66) increased risk of duodenal ulcer in females compared to those with the $5 \mathrm{~A}$ carrier. Because TIMP-1 genotypes modulated MMP-3 activity, it was further tested whether the MMP- $3_{-1612} /$ TIMP $-1_{372}$ Combined genotypes contributed to increased risk of duodenal ulcers in females. The combined MMP-3/ TIMP-1 genotype as 6A6A/CC had a 3.6-fold $(p<0.05)$ increased risk of duodenal ulcer in $H$. pylori-infected female (Table 4).

\section{Discussion}

This study surveyed whether the bacterial factor $d u p A$ in $H$. pylori or single nucleotide polymorphisms of MMPs and TIMPs correlated with the susceptibility of gastroduodenal ulcers after $H$. pylori infection. It shows a rather low prevalence (23.8\%) of $d u p A$-positive $H$. pylori infection in Taiwan. Moreover, such a low prevalence limits its association to susceptibility to gastroduodenal ulcers after $H$. pylori infection.
The negative finding is consistent with several studies worldwide $[8,10,11]$ but differs from $\mathrm{Lu}$ et al., who support the promoting role of $H$. pylori $d u p A$ [6]. In their positive report [6], $d u p A$-positive prevalence is nearly $50 \%$ and it can be attributed as the promoting role of ulceration. Their data suggest that there should be some other bacterial virulence factor of $H$. pylori as $C a g A$, $b a b A 2$, vacA, or host factors, which determine the susceptibility of ulceration. In Taiwan, there is nearly a $100 \%$ prevalence of $C a g A, b a b A 2$, vacA triple-positive infection $[4,15]$. The current study area should be a good place to validate the host factor predisposing to ulcer risk.

In the in vitro promoter functional assay of fibroblasts and vascular smooth muscle cells, the MMP-3 -1612 as $5 \mathrm{~A}$ allele has greater promoter activities than the $6 \mathrm{~A}$ allele [19]. This implies that patients carrying the lower promoter activity genotype 6A6 in the MMP-3 promoter are accompanied by lower MMP-3 expressions of the 


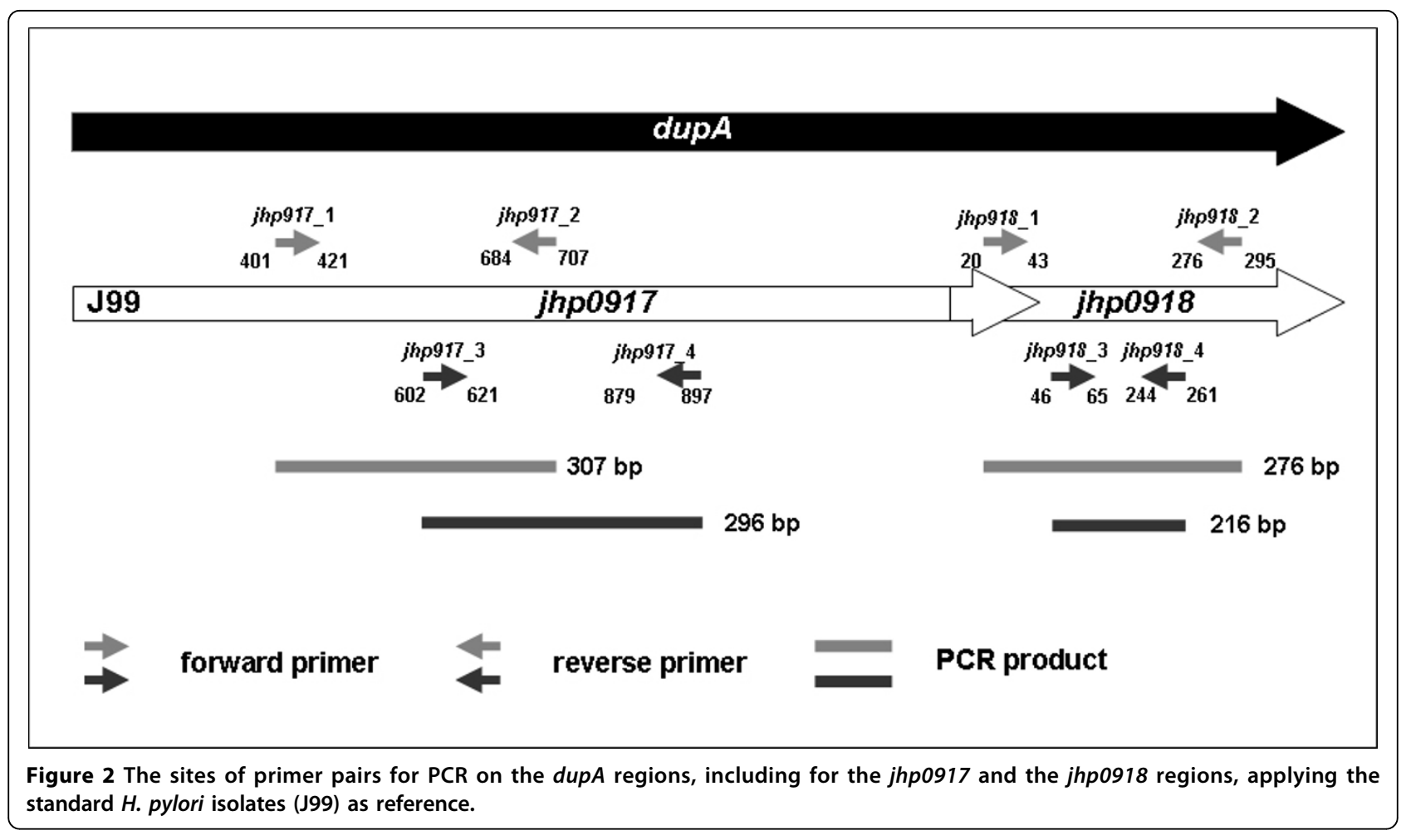

gastric mucosa. This study discloses the host genotype MMP-3 -1612 as 6A6A, which expresses lower MMP-3 carries a 2.4-fold risk of having duodenal ulcers among females after $H$. pylori infection $(p<0.05)$ (Table 3$)$. Moreover, TIMP-1 372, as CC, contributes a higher risk of duodenal ulcers to MMP-3 -1612 6A6A (Table 4). This data suggests that patients with higher MMP-3 expression may have lower ulcer risk, but the reasons remain uncertain.

In general, MMP-3 can degrade a wide range of substrates, including fibronectin, type IV, V, IX, and $\mathrm{X}$ collagens, elastin, laminins, gelatin, and proteoglycan core proteins, and is thus helpful during wound healing of the skin [27-29]. Moreover, the gastric mucosa at the ulcer site also has significantly higher expression of MMP-3 than those in the antrum [30], which suggests MMP-3 is abundant in the ulcer part, and this may help the process of re-epithelialization and contribute to wound healing.

Hellmig et al. disclose the positive associations of MMP-7 promoter -181 and MMP-9 exon 6 SNPs to the presence of gastric ulcer among Germans [17]. However,

Table 2 Demographic and histologic characteristics of $\boldsymbol{H}$. pylori-infected patients with single nucleotide polymorphism analysis $(n=470)$

\begin{tabular}{|c|c|c|c|c|}
\hline Parameters & $\begin{array}{l}\text { Gastritis } \\
(n=265)\end{array}$ & $\begin{array}{l}\text { Duodenal ulcer } \\
\quad(n=118)\end{array}$ & $\begin{array}{c}\text { Gastric ulcer } \\
(\mathrm{n}=87)\end{array}$ & $p$ value \\
\hline Age, mean (SD) (yr) & $46.9(13.7)$ & $47.6(14.0)$ & $47.8(11.7)$ & NS \\
\hline \multicolumn{5}{|l|}{ Gender, n (\%) } \\
\hline Female: Male & 183 (69.1): 82 (30.9) & $57(48.3): 61(51.7)$ & $36(41.4): 51(58.6)$ & $p^{a}<0.05 ; p^{b}<0.05$ \\
\hline \multicolumn{5}{|l|}{ Histology score, mean (SD) } \\
\hline \multicolumn{5}{|l|}{ (Antrum) } \\
\hline AIS (range 1-3) & $1.18(0.99)$ & $1.39(0.95)$ & $0.99(1.03)$ & $p^{c}<0.05$ \\
\hline CIS (range $0-3$ ) & $2.34(1.01)$ & $2.56(0.89)$ & $2.05(1.17)$ & $p^{a}<0.05 ; p^{b}<0.05 ; p^{c}<0.05$ \\
\hline \multicolumn{5}{|l|}{ (Corpus) } \\
\hline AIS (range 1-3) & $0.85(0.99)$ & $0.72(0.95)$ & $0.86(1.06)$ & NS \\
\hline CIS (range $0-3$ ) & $2.24(0.86)$ & $2.15(0.83)$ & $2.13(0.89)$ & NS \\
\hline
\end{tabular}

Abbreviations: AIS, acute inflammation; CIS, chronic inflammation. The $p$ value was determined by $t$ test (age), $\chi^{2}$ test (gender) or Mann-Whitney $\mathrm{U}$ test (histology score). ${ }^{a}$ indicated significance with $p<0.05$ of such parameter between gastritis and duodenal ulcer; ${ }^{\text {b }}$ between gastritis and gastric ulcer; ${ }^{\mathrm{c}}$ between duodenal ulcer and gastric ulcer. NS: no significant difference. 


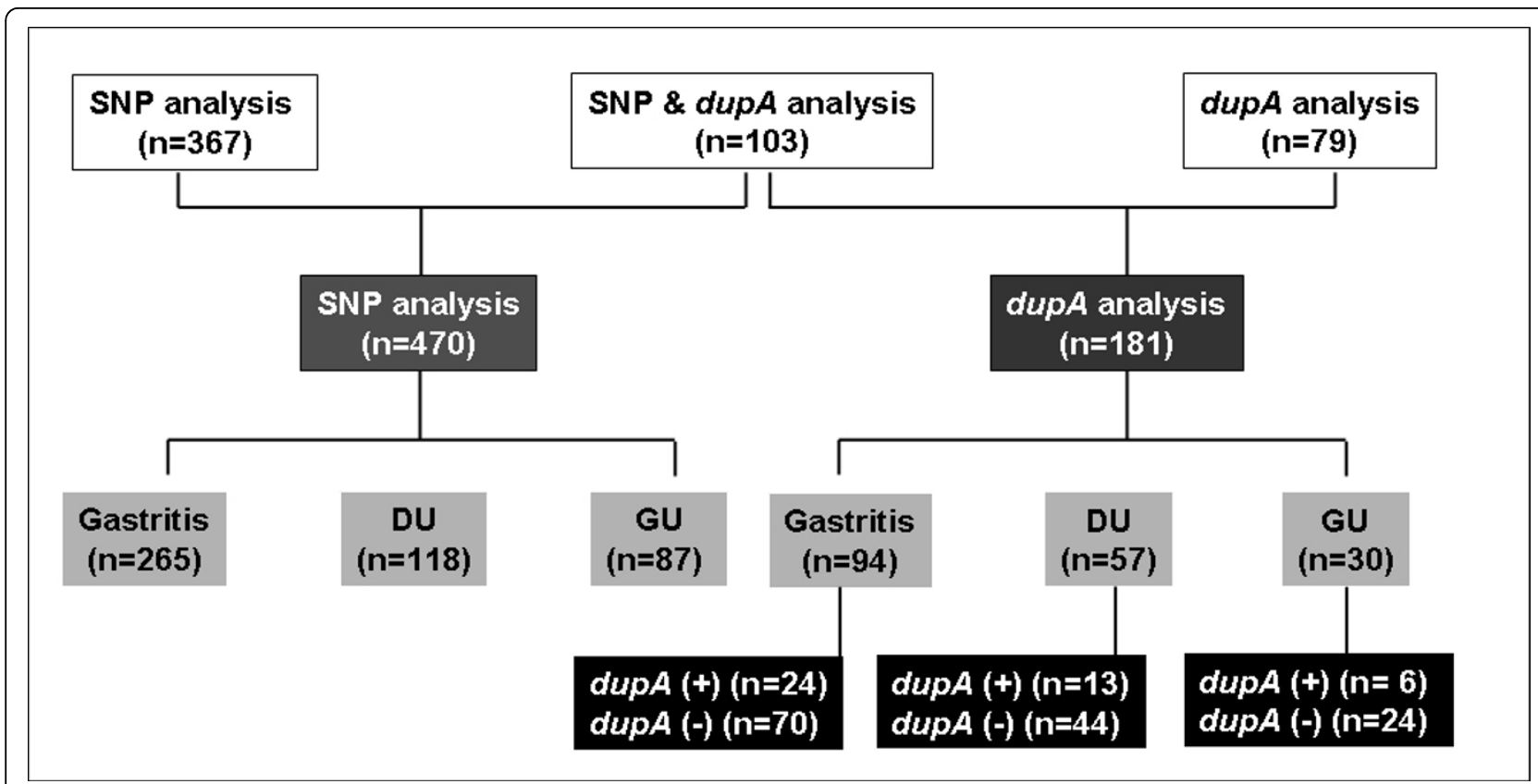

Figure 3 The study patients and their H. pylori-dupA status.

this may be due to distinct ethnic or racial variations and such positive linkage is not disclosed in the current study from Taiwan.

This is the first report to show that there is no direct association between the genotypes of TIMP-1 372 at exon 5 and TIMP- 2 at promoter -418 , and the presence of gastroduodenal ulcers (Table 3). However, because TIMP-1 genotypes may modulate MMP-3 activity, further testing if the MMP- $3_{-1612} /$ TIMP $1_{372}$ Combined genotypes contribute to increased risk of duodenal ulcers shows that the combined MMP-3/TIMP-1 genotype as $6 \mathrm{~A} 6 \mathrm{~A} / \mathrm{CC}$ has a 3.6 -fold increased risk of duodenal ulcer $(p<0.05)$ in $H$. pylori-infected females. This data suggests that TIMP-1 may also have a supportive role in interacting with MMP-3 during ulcerogenesis by H. pylori infection, especially in females.

Table 3 The SNP genotypes of MMPs and TIMPs in the both genders with different clinical diagnoses

\begin{tabular}{|c|c|c|c|c|c|c|c|c|c|c|c|}
\hline \multirow{2}{*}{$\begin{array}{l}\text { Genotype } \\
\text { N (\%) }\end{array}$} & & \multicolumn{5}{|c|}{ Female } & \multicolumn{5}{|c|}{ Male } \\
\hline & & Gastritis & DU & GU & $P^{a}$ & $P^{b}$ & Gastritis & DU & GU & $P^{a}$ & $P^{b}$ \\
\hline \multicolumn{12}{|l|}{ MMP-3 } \\
\hline $5 \mathrm{~A}$ carrier & & $46(25.1)$ & 7 (12.3) & $8(22.2)$ & 0.04 & 0.71 & $28(34.1)$ & $15(24.6)$ & $11(21.6)$ & 0.22 & 0.12 \\
\hline $6 \mathrm{~A} / 6^{\mathrm{a}}$ & & $137(74.9)$ & $50(87.7)$ & $28(77.8)$ & & & $54(65.9)$ & $46(75.4)$ & $40(78.4)$ & & \\
\hline \multicolumn{12}{|l|}{ MMP-7 } \\
\hline $\mathrm{A} / \mathrm{A}$ & & $150(82.9)$ & $45(80.4)$ & 32 (91.4) & & 0.31 & $72(88.9)$ & $52(86.7)$ & $39(76.5)$ & 0.69 & 0.06 \\
\hline G carrier & & 31 (17.1) & 11 (19.6) & $3(8.6)$ & 0.67 & & 9 (11.1) & 8 (13.3) & $12(23.5)$ & & \\
\hline \multicolumn{12}{|l|}{ MMP-9 } \\
\hline A carrier & & 78 (42.6) & 19 (33.3) & $15(41.7)$ & 0.21 & 0.92 & $25(30.5)$ & $22(36.1)$ & $22(43.1)$ & 0.48 & 0.14 \\
\hline $\mathrm{G} / \mathrm{G}$ & & $105(57.4)$ & $38(66.7)$ & $21(58.3)$ & & & $57(69.5)$ & 39 (63.9) & $29(56.9)$ & & \\
\hline \multicolumn{12}{|l|}{ TIMP-1 } \\
\hline O T carrier & $\sigma^{n} T$ & $148(80.9)$ & 41 (73.2) & 29 (80.6) & 0.22 & 0.97 & $46(56.8)$ & 31 (50.8) & $26(51.0)$ & 0.48 & 0.51 \\
\hline $\mathrm{C} / \mathrm{C}$ & C & 35 (19.1) & $15(26.8)$ & 7 (19.4) & & & $35(43.2)$ & $30(49.2)$ & $25(49.0)$ & & \\
\hline \multicolumn{12}{|l|}{ TIMP-2 } \\
\hline C carrier & & $54(30.2)$ & $17(32.1)$ & 10 (28.6) & 0.79 & 0.85 & $27(33.3)$ & $20(32.3)$ & $13(25.5)$ & 0.89 & 0.34 \\
\hline $\mathrm{G} / \mathrm{G}$ & & $125(69.8)$ & $36(67.9)$ & 25 (71.4) & & & $54(66.7)$ & $42(67.7)$ & $38(74.5)$ & & \\
\hline
\end{tabular}

Abbreviations: DU, duodenal ulcer; GU, gastric ulcer. The $p$ value was determined by Fisher's exact test or $\chi^{2}$ test. ${ }^{a}$ indicated significance with $p<0.05$ of such parameter between gastritis and duodenal ulcer; ${ }^{\mathrm{b}}$ between gastritis and gastric ulcer. Genotype distribution of SNP in cases and control was in Hardy-Weinberg equilibrium $(p<0.05)$. 
Table 4 Risks of combined MMP-3/TIMP-1 genotype for developing duodenal ulcer in females

\begin{tabular}{lcccc}
\hline MMP-3-1612- TIMP-1 $\mathbf{3 7 2}_{\mathbf{2}}$ & Gastritis & Duodenal ulcer & OR (95\% Cl) & $\mathbf{P}$ \\
\hline 5A carrier - T carrier & $\mathbf{n}(\%)$ & $\mathbf{n}(\%)$ & 1 & - \\
5A carrier - C/C & $39(88.6)$ & $5(11.4)$ & $2.23(0.36-13.85)$ & 0.59 \\
6A/6A - T carrier & $7(77.8)$ & $2(22.2)$ & $2.58(0.94-7.03)$ & 0.06 \\
6A/6A - C/C & $109(75.2)$ & $36(24.8)$ & $3.62(1.16-11.32)$ & 0.03 \\
\hline
\end{tabular}

The $p$ value was determined by Fisher's exact test. OR, odds ratio; $95 \% \mathrm{Cl}, 95 \%$ confidence interval.

However, the exact reason why such a combined MMP-3/TIMP-1 genotype as 6A6A/CC has just an increased risk of duodenal ulcer in $H$. pylori-infected females, but not in male, remains uncertain. If such a regulation between MMP-3 and TIMP-1 play a role in female's ulceration, our data at least imply some other host or environment factors in male should be more dominant than such combined genotype.

The study has a limitation of just providing 181 isolates for the analysis of the $\operatorname{dupA}$ status of $H$. pylori, which disclose a rather low $20 \% d u p A$-positive prevalence rate. Accordingly, the study became limited to only 103 patients to provide both analyses on the infected isolate's dupA status and the host's SNPs (Figure 2). It thus cannot provide an adequate statistical power to determine the exact impact of MMP-3 SNPs under $d u p A$-negative specific conditions.

\section{Conclusions}

In conclusion, this study provides evidence that host promoter polymorphisms of MMP-3 contribute to increased individual susceptibility to duodenal ulcers in females after H. pylori infection in Taiwan. The MMP-3 promoter genotypes may serve to screen out patients at risk and target for $H$. pylori eradication in order to stop the ulceration process among $H$. pylori-infected patients without ulcers yet.

\section{Acknowledgements}

This study was supported by grants from the National Science Council, Taiwan (95-2314-B-006-029-MY3 and 98-2628-B-006-013-MY3), NHRI-EX999908BI from the National Health Research Institute, and DOH99-TD-C-111003 from Department of Health, Taiwan. The authors also thank Miss HuntWen Wu for her assistance.

\section{Author details}

${ }^{1}$ Institute of Basic Medical Sciences, National Cheng Kung University Hospital, Medical College, Tainan. ${ }^{2}$ Institute of Clinical Medicine, National Cheng Kung University Hospital, Medical College, Tainan. ${ }^{3}$ Department of Internal

Medicine, National Cheng Kung University Hospital, Medical College, Tainan. ${ }^{4}$ Department of Pathology, National Cheng Kung University Hospital, Medical College, Tainan. ${ }^{5}$ Department of Pathology, Ton-Yen General Hospital, HsinChu, Taiwan.

\section{Authors' contributions}

YCY prepared the manuscript, and carried out the molecular genetic studies to the host SNPs and dupA genotyping for the collected isolates of $\mathrm{H}$. pylori. HCC and WLC carried out the SNP analysis and clinical specimen collection during endoscopy. HBY participated in the design of the study, performed the analysis of pathology, and statistical analysis. BSS conceived of the whole study, and participated in its design and coordination. All authors read and approved the final manuscript.

Received: 24 March 2010 Accepted: 13 August 2010

Published: 13 August 2010

\section{References}

1. Labigne A, de Reuse H: Determinants of Helicobacter pylori pathogenicity. Infect Agents Dis 1996, 5(4):191-202.

2. Maeda S, Mentis AF: Pathogenesis of Helicobacter pylori infection. Helicobacter 2007, 12(Suppl 1):10-14.

3. Prinz C, Schwendy S, Voland P: H. pylori and gastric cancer: shifting the global burden. World J Gastroenterol 2006, 12(34):5458-5464.

4. Sheu BS, Odenbreit S, Hung KH, Liu CP, Sheu SM, Yang HB, Wu JJ: Interaction between host gastric Sialyl-Lewis $X$ and $H$. pylori SabA enhances $H$. pylori density in patients lacking gastric Lewis $B$ antigen. Am J Gastroenterol 2006, 101(1):36-44.

5. Lai $\mathrm{CH}$, Kuo CH, Chen YC, Chao FY, Poon SK, Chang CS, Wang WC: High prevalence of cagA- and babA2-positive Helicobacter pylori clinical isolates in Taiwan. J Clin Microbiol 2002, 40(10):3860-3862.

6. Lu H, Hsu PI, Graham DY, Yamaoka Y: Duodenal ulcer promoting gene of Helicobacter pylori. Gastroenterology 2005, 128(4):833-848.

7. Schmidt HM, Andres S, Nilsson C, Kovach Z, Kaakoush NO, Engstrand L, Goh KL, Fock KM, Forman D, Mitchell H: The cag PAl is intact and functional but HP0521 varies significantly in Helicobacter pylori isolates from Malaysia and Singapore. Eur J Clin Microbiol Infect Dis 2010, 29(4):439-451.

8. Nguyen LT, Uchida T, Tsukamoto Y, Kuroda A, Okimoto T, Kodama M, Murakami K, Fujioka T, Moriyama M: Helicobacter pylori dupA gene is not associated with clinical outcomes in the Japanese population. Clin Microbiol Infect 2010, 16(8):1264-1269.

9. Hussein NR: The association of dupA and Helicobacter pylori-related gastroduodenal diseases. Eur J Clin Microbiol Infect Dis 2010, 29(7):817-821.

10. Gomes LI, Rocha GA, Rocha AM, Soares TF, Oliveira CA, Bittencourt PF, Queiroz DM: Lack of association between Helicobacter pylori infection with dupA-positive strains and gastroduodenal diseases in Brazilian patients. Int J Med Microbiol 2008, 298(3-4):223-230.

11. Argent $\mathrm{RH}$, Burette $\mathrm{A}$, Miendje Deyi $\mathrm{VY}$, Atherton JC: The presence of dupA in Helicobacter pylori is not significantly associated with duodenal ulceration in Belgium, South Africa, China, or North America. Clin Infect Dis 2007, 45(9):1204-1206.

12. Chang YT, Wu MS, Shun CT, Lin MT, Chang MC, Lin JT: Association of polymorphisms of interleukin-1 beta gene and Helicobacter pylori infection with the risk of gastric ulcer. Hepatogastroenterology 2002, 49(47):1474-1476.

13. Visse $\mathrm{R}$, Nagase $\mathrm{H}$ : Matrix metalloproteinases and tissue inhibitors of metalloproteinases: structure, function, and biochemistry. Circ Res 2003, 92(8):827-839.

14. Yeh YC, Sheu BS, Cheng HC, Wang YL, Yang HB, Wu JJ: Elevated serum matrix metalloproteinase-3 and -7 in $\mathrm{H}$. pylori-related gastric cancer can be biomarkers correlating with a poor survival. Dig Dis Sci 2010, 55(6):1649-1657.

15. Mori N, Sato H, Hayashibara T, Senba M, Geleziunas R, Wada A, Hirayama T, Yamamoto N: Helicobacter pylori induces matrix metalloproteinase-9 through activation of nuclear factor kappaB. Gastroenterology 2003, 124(4):983-992.

16. Crawford HC, Krishna US, Israel DA, Matrisian LM, Washington MK, Peek RM Jr: Helicobacter pylori strain-selective induction of matrix 
metalloproteinase-7 in vitro and within gastric mucosa. Gastroenterology 2003, 125(4):1125-1136.

17. Hellmig S, Ott S, Rosenstiel P, Robert Folsch U, Hampe J, Schreiber S: Genetic variants in matrix metalloproteinase genes are associated with development of gastric ulcer in $\mathrm{H}$. pylori infection. Am J Gastroenterol 2006, 101(1):29-35.

18. Jormsjo S, Whatling C, Walter DH, Zeiher AM, Hamsten A, Eriksson P: Allelespecific regulation of matrix metalloproteinase-7 promoter activity is associated with coronary artery luminal dimensions among hypercholesterolemic patients. Arterioscler Thromb Vasc Biol 2001, 21(11):1834-1839.

19. Ye S, Eriksson P, Hamsten A, Kurkinen M, Humphries SE, Henney AM: Progression of coronary atherosclerosis is associated with a common genetic variant of the human stromelysin-1 promoter which results in reduced gene expression. J Biol Chem 1996, 271(22):13055-13060.

20. Shipley JM, Doyle GA, Fliszar CJ, Ye QZ, Johnson LL, Shapiro SD, Welgus HG Senior RM: The structural basis for the elastolytic activity of the $92-k D a$ and $72-\mathrm{kDa}$ gelatinases. Role of the fibronectin type II-like repeats. J Biol Chem 1996, 271(8):4335-4341.

21. Clark IM, Swingler TE, Sampieri CL, Edwards DR: The regulation of matrix metalloproteinases and their inhibitors. Int J Biochem Cell Biol 2008, 40(6-7):1362-1378.

22. Sheu BS, Sheu SM, Yang HB, Huang AH, Wu JJ: Host gastric Lewis expression determines the bacterial density of Helicobacter pylori in babA2 genopositive infection. Gut 2003, 52(7):927-932.

23. Dixon MF, Genta RM, Yardley JH, Correa P: Classification and grading of gastritis. The updated Sydney System. International Workshop on the Histopathology of Gastritis, Houston 1994. Am J Surg Pathol 1996, 20(10):1161-1181.

24. Shibata N, Ohnuma T, Higashi S, Usui C, Ohkubo T, Kitajima A, Ueki A, Nagao $M$, Arai $\mathrm{H}$ : Genetic association between matrix metalloproteinase MMP-9 and MMP-3 polymorphisms and Japanese sporadic Alzheimer's disease. Neurobiol Aging 2005, 26(7):1011-1014.

25. Zhou Y, Yu C, Miao X, Tan W, Liang G, Xiong P, Sun T, Lin D: Substantial reduction in risk of breast cancer associated with genetic polymorphisms in the promoters of the matrix metalloproteinase- 2 and tissue inhibitor of metalloproteinase-2 genes. Carcinogenesis 2004 25(3):399-404

26. Wollmer MA, Papassotiropoulos A, Streffer JR, Grimaldi LM, Kapaki E, Salani G, Paraskevas GP, Maddalena A, de Quervain D, Bieber C, et al: Genetic polymorphisms and cerebrospinal fluid levels of tissue inhibitor of metalloproteinases 1 in sporadic Alzheimer's disease. Psychiatr Genet 2002, 12(3):155-160.

27. Bullard KM, Mudgett J, Scheuenstuhl H, Hunt TK, Banda MJ: Stromelysin-1deficient fibroblasts display impaired contraction in vitro. I Surg Res 1999, 84(1):31-34.

28. Saarialho-Kere UK: Patterns of matrix metalloproteinase and TIMP expression in chronic ulcers. Arch Dermatol Res 1998, 290(Suppl):S47-54.

29. Madlener M: Differential expression of matrix metalloproteinases and their physiological inhibitors in acute murine skin wounds. Arch Dermatol Res 1998, 290(Suppl):S24-29.

30. Tomita M, Ando T, Minami M, Watanabe $\mathrm{O}$, Ishiguro K, Hasegawa M, Miyake N, Kondo S, Kato T, Miyahara R, et al: Potential role for matrix metalloproteinase-3 in gastric ulcer healing. Digestion 2009, 79(1):23-29.

\section{Submit your next manuscript to BioMed Central and take full advantage of:}

- Convenient online submission

- Thorough peer review

- No space constraints or color figure charges

- Immediate publication on acceptance

- Inclusion in PubMed, CAS, Scopus and Google Scholar

- Research which is freely available for redistribution

Submit your manuscript at www.biomedcentral.com/submit
Biomed Central 